\title{
ПРОБЛЕМИ ПІДГОТОВКИ МАЙБУТНІХ ФАХІВЦІВ 3 ПРИКЛАДНОЇ МЕХАНІКИ ДО ВИКОРИСТАННЯ МОБІЛЬНИХ І ХМАРНИХ ТЕХНОЛОГІЙ У ПРОФЕСІЙНІЙ ДІЯЛЬНОСТІ
}

Рассовицька М. В. Проблеми підготовки майбутніх фахівців з прикладної механіки до використання мобільних і хмарних технологій у професійній діяльності.

Метою статті є виділення мобільних і хмаро орієнтованих засобів, які доиільно використовувати для професійно-практичної підготовки майбутніх фахівиів з прикладної механіки, та особливостей їх системного використання у вищих технічних навчальних закладах Украӥни. В роботі проаналізовано сучасні хмарні сервіси та мобільні програми, що можуть бути використані в професійній діяльності інженерів-механіків. Визначено, що використання хмарних сервісів Autodesk та їх інтеграиія з хмарними сервісами Google $\epsilon$ доиільним для професійно-практичної підготовки бакалаврів з прикладної механіки. Запропоновано модель єдиного доступу до хмарних сервісів загальнонаукової, навчальної та професійної діяльності.

Ключові слова: ІКТ-компетентність, прикладна механіка, мобільні технології, хмарні технологї, САПР, професійно-практична підготовка.

Рассовицкая М. В. Проблемы подготовки будущих специалистов в прикладной механике к использованию мобильных и облачных технологий в профессиональной деятельности.

Целью статьи является выделение мобильных и облако ориентированных средств, которые целесообразно использовать для профессиональнопрактической подготовки будущчих специалистов в прикладной механике, $и$ особенностей их системного использования в высших технических учебных заведениях Украины. В работе проанализированы современные облачные сервисы и мобильные приложения, используемые в профессиональной деятельности инженеров-механиков. Определено, что наиболее иелосообразно использование сервисов Autodesk и их интеграчия с сервисами Google. Предложена модель единого доступа к облачным сервисам в-научной, учебной и профессиональной деятельности бакалавров прикладной механики.

Ключевые слова: ИКТ-компетентность, прикладная механика, мобильные технологии, облачные технологии, САПР, профессионально-практическая подготовка. 
Rassovytska M. V. Problems of training of future specialists in applied mechanics to use mobile and cloud technologies in their professional activities.

Introduction. From specialist required formed a high-level ICT competence, capability and ability to use existing software for solving problems using local resources and global computer networks, collaboration skills, the use of cloud and mobile technologies in engineering activity. In this regard, steadily growing requirements for Ukraine universities future engineer ICT training.

Purpose. Allocation of mobile and cloud-oriented tools that should be used for professional and practical training of future specialists in applied mechanics and specifics of their use of the system of higher technical educational institutions of Ukraine.

Methods. Analysis of educational programs, analysis of scientific literature, a survey of students and teachers, modeling.

Results. The identified of influence cloud technology on methodical system of computing disciplines training for future professionals of applied mechanics. A model using Google Apps in training bachelors of applied mechanics and model of a typical access to cloud-oriented means of general scientific, educational and professional activities has been offered. Analyzed the current cloud services and mobile applications that can be used for the profession of mechanical engineers.

Originality. A model using Google Apps in training bachelors of applied mechanics. A model of a typical access to cloud-oriented means of general scientific, educational and professional activities. Using of Autodesk cloud services and their integration with cloud services Google is appropriate for future specialists in applied mechanics professional and practical training model.

Conclusion. It is proved that the use of Autodesk cloud services and their integration with cloud services Google is appropriate for future specialists in applied mechanics professional and practical training. Results of the study can be applied to vocational and practical training of students of other engineering specialties.

Keywords: ICT competence, applied mechanics, cloud technology, CAD, vocational and practical training.

Вимоги до рівня інформатичної підготовки майбутніх фахівців 3 прикладної механіки невпинно зростають у зв'язку з постійним розвитком старих, появою нових комп’ютерних засобів та високою інклюзією інформаційно-комунікаційних технологій у професійну діяльність сучасного інженера. Найбільш ярко вираженою $\epsilon$ сучасна тенденція широкого використання мобільних та хмаро орієнтованих ІКТ під час оформлення конструкторської документації, виконання розрахунків, табличних обчислень, управління складними проектами та моделями тощо [6]. Тому підготовка конкурентоспроможних фахівців сьогодні не можлива без формування навичок 
та вмінь використання хмарних і мобільних технологій в інженерній діяльності $[7 ; 9]$.

Метою даної статті є виділення мобільних і хмаро орієнтованих засобів, які доцільно використовувати для професійно-практичної підготовки майбутніх фахівців з прикладної механіки, та особливостей їх системного використання у вищих технічних навчальних закладах України.

Відповідно до мети статті ми намагалися вирішити наступні задачі:

- визначити місце та роль мобільних і хмарних технологій у професійній діяльності інженерів-механіків;

- виконати добір мобільних і хмаро орієнтованих засобів професійної діяльності інженерів-механіків з метою їх використання у навчальному процесі;

- запропонувати системний підхід до використання виділених засобів у професійно-практичній підготовці майбутніх фахівців з прикладної механіки.

В процесі дослідження ми спирались на теоретичні та методичні аспекти сучасної підготовки фахівців інженерних спеціальностей, які досліджувались Н. А. Моїсеєнко, В. П. Куликовим, О. М. Шевченко, Н. С. Пономарьовою, Р. Р. Ібраєвим, М. Ю. Порхачевим, Г. І. Шабановим, О. І. Ананьєвою, Д. О. Костяновим, М. Д. Аптекарем, І. О. Гончаровою; на методичні принципи використання мобільних i хмарних технологій у навчанні присвячені, запропоновані в роботах В. Ю. Бикова, Н. В. Морзе, 3. С. Сейдаметової, О. М. Спіріна, А. М. Стрюка, Ю. В. Триуса, М. П. Шишкіної та ін.

Програма підготовки майбутніх інженерів-механіків передбачає формування навичок використання текстових та графічних матеріалів за допомогою існуючого програмного забезпечення; пошуку та систематизації наукових та технічних даних за допомогою програмного забезпечення та комп'ютерних мереж; вибору необхідного стандартного програмного забезпечення або складання необхідної програми; формалізації та алгоритмізації розв’язання загально інженерних задач; використання автоматизованого робочого місця та обробки графічної інформації із застосуванням комп'ютерних технологій. Аналіз сучасних вимоги суспільства 
до професійної діяльності інженерів механіків надав можливість виділити зростаючу потребу у кваліфікованих інженерах на ряду 3 необхідністю забезпечити їх різносторонню мобільність: професійну, географічну тощо. Таким чином, основними критеріями добору мобільних і хмаро орієнтованих засобів професійної діяльності інженерів-механіків з метою їх використання у навчальному процесі, стала їх функціональність, доступність, зручність доступу 3 різних пристроїв, можливість інтеграції з іншими програмними продуктами, підтримка спільної роботи та інтеграція з іншими хмарними сервісами.

Нами було проаналізовано близько 30 сучасних хмарних сервісів i мобільних програм, що можуть бути використані в професійній діяльності інженерів-механіків. Серед них найбільш відомими є, А360, Fusion 360, GstarCAD DWG FastView, CAD Pockets, 3D CAD Models Engineering, CAD Assistant, Onshape, GrabCAD, GnaCAD та iн. Розглянуті програмні продукти пропонують достатньо функцій для спільної роботи 3 кресленнями, їх перегляду, коментування, зберігання в хмарних сховищах. Але всі вони орієнтуються на підтримку форматів і технологій, запроваджених компанією Autodesk, тому ми звернули найбільшу увагу на програмні продукти, що пропонуються цією компанією.

Вже понад 30 років компанія AutoDesk є світовим лідером у виробництві систем автоматизованого проектування [2]. Найвідомішими продуктами компанії є AutoCAD, 3ds Max, Мауа. Популярність продукти AutoDesk здобули завдяки широкому функціоналу, наявністю великої кількості бібліотек та конфігурацій, а також інтеграцією 3 різними середовищами проектування, моделювання, управління проектами, тощо. Зокрема для інженерів-механіків компанія пропонує версію AutoCAD Mechanical [3]. Autodesk одними з перших оцінили потенціал хмарних технологій для задач автоматизованого проектування i моделювання i на сьогодні пропонують широкий спектр хмарних сервісів та мобільних програм, що можуть стати зручним і ефективним інструментом як для вирішення виробничих інженерних задач, так i для навчання майбутніх фахівців. 
Хмарний сервіс A360 [5] компанії Autodesk надає можливість спільно працювати 3 2D i 3D-проектами різної складності. Він підтримує більше 50 форматів файлів САПР, включаючи формати Autodesk, SolidWorks, CATIA, Pro-E, Rhino i NX.

Серед основних можливостей А360 слід відзначити наступні:

- вивантаження і перегляд моделей САПР з вкладень електронної пошти;

- вивантаження і перегляд моделей САПР з внутрішньої пам'яті пристрою, Dropbox, Box, Buzzsaw, OneDrive і т. д.;

- навігація по великомасштабним 2D і 3D-моделям САПР;

- вимірювання відстані, кута і площі по точках на кресленні;

- інтуїтивно-зрозумілі сенсорні функції навігації по 3D-моделі, в тому числі масштабування, панорамування, обліт по орбіті та поворот;

- єдиний інструмент для спільної роботи 3 колегами та іншими користувачами;

- перевірка і позначка проектів для спрощення спільної роботи;

- коментування проектів і відстеження змін;

- документування ходу робіт шляхом вивантаження зроблених фотознімків з пристрою в обліковий запис;

- надсилання запрошень користувачам для участі в поточному проекті і спільної роботи над іншими проектами;

- надання загального доступу до файлів САПР безпосередньо з пристрою Android, в тому числі до AutoCAD (DWG), DWF, SolidWorks, Revit, CATIA i т. д.

- визначення статусу проекту в будь-який час і в будь-якому місці;

- хмарне сховище з підтримкою автономного доступу до даних;

- підтримка роботи в автономному та онлайн-режимах, завдяки чому учасники проекту завжди можуть бути в курсі змін і оновлень;

AutoCAD 360 [1] - це хмарна версія одного 3 найбільш потужних i популярних програмних комплексів для автоматизованого проектування. безкоштовний мобільний додаток, створений компанією Autodesk Inc. Biн має 
набір простих у використанні інструментів, які дозволяють переглядати, створювати, редагувати і обмінюватися кресленнями AutoCAD через мобільні пристрої. Програма надає можливість завантажувати i відкрити 2D DWG креслень безпосередньо 3 електронної пошти або зовнішнього накопичувача. Оновлення до AutoCAD 360 Pro надає можливість редагувати та виводити креслення інструментів.

AutoCAD 360 Pro пропонує користувачам наступні можливості:

- відкривати і переглядати файли у форматі DWG;

- робити вимірювання у реальному часі;

- переглядати координати на кресленні;

- використовувати масштабування і панорамування, легко переміщатися по малюнку великого розміру;

- працювати в автономному режимі та синхронізувати зміни он-лайн;

- підключатися до хмарних систем зберігання даних Google Drive, Dropbox та OneDrive;

- використовувати GPS, для того щоб орієнтуватися в кресленні;

- ділитися своїми проектами 3 іншими користувачами безпосередньо 3 мобільного телефону;

- обмінюватися конструкціями в PDF або DWF форматі через електронну пошту;

- використовувати безкоштовний веб-додаток для отримання малюнків 3 веб-браузерів.

Для використання в навчальному процесі доступний повнофункціональна версія AutoCAD 360 Pro, що надає можливості:

- створення нового креслення;

- підтримувати файли великих розмірів;

- більше інструментів для малювання та редагування, включаючи передові інструменти, такі як дуги, зміщення і багато іншого;

- малювати i редагувати форми 3 точністю за допомогою об'єктної прив'язки і нової функції клавіатури (клавіатура доступна тільки на IPad); 
- вибирати, переміщати, обертати і масштабувати об'єкти;

- редагувати безпосередньо файлів які зберігаються у зовнішній хмарі;

- додавати і редагувати текст анотації безпосередньо на кресленні;

- користуватися розширеними засобами анотацій - хмара, розмітити, стрілка і багато іншого;

- переглядати і редагувати властивості об'єктів;

- вставляти всі існуючі блоки з креслення.

Додаток Fusion 360 [3] який також розроблений компанією Autodesk, надає можливість співпрацювати з 3D проектами, а саме переглядати, розмічати, коментувати, i спільно працювати з CAD моделями в будь-який час і в будьякому місці. Програма підтримує більше 100 форматів файлів, включаючи DWG, SLDPRT, IPT, IAM, CATPART, IGES, STEP, STL. Безкоштовний додаток працює в поєднанні з її супутником Autodesk Fusion 360, 3D CAD, CAM i CAE інструментом для проектування і розробки моделей на основі хмари.

Основні можливості Fusion 360:

- огляд різних за розміром 3D конструкцій та їх об’єднання;

- перегляд проектів різних форматів;

- вимірювання відстані, площі чи кута між точками в 2D або 3D кресленнях;

- доступ до повних списків деталей;

- ізолювати і приховати компоненти в моделі для зручності перегляду;

- панорамування і поворот;

- оглядати та розмічати конструкції для зручної співпраці;

- коментувати конструкції;

- ділитися інформацією з зацікавленими сторонами.

Програма AutoCAD Mechanical [4] створена для проектування в машинобудуванні і $\epsilon$ актуальним розширенням традиційного AutoCAD для інженерів-механіків. Розроблена також компанією Autodesk, вона містить всі функції AutoCAD, а також бібліотеки стандартних деталей і інструментів, що дозволяють прискорити роботу САПР для машинобудування. 
Використовуючи AutoCAD Mechanical, фахівці з прикладної механіки отримують наступні можливості:

- користуватися повним набором функцій AutoCAD;

- використовувати особливі засоби креслення;

- застосовувати близько 700000 стандартних деталей і компонентів;

- отримувати креслення у відповідності державних стандартів;

- використовувати генератори компонентів і розрахункові модулі;

- використовувати «інтелектуальні» розміри;

- використовувати функцію автоматичного приховування ліній;

- користуватись асоціативними номерами позицій і специфікацій;

- застосовувати інтегроване управління даними.

Мобільна програма A360 - View \& Markup CAD files створена для спільної роботи з 2D і 3D та CAD моделями за допомогою мобільних пристроїв та планшетів. Підтримує більше $100 \mathrm{CAD}$ файлів різних форматів. A360 дозволяє завантажувати і переглядати будь-який файл незалежно від того, яке програмне забезпечення використовується для його створення. Програма функціонально доповнює вищезгадане програмне забезпечення і підтримує більше 50 різних форматів файлів САПР, включаючи: AutoCAD (DWG), DWF, Inventor (IPT, IAM, IDW), Revit (RVT), SolidWorks (SLDPRT, SLDASM, ASM), Navisworks (NWD, NWC), CATIA (CATPART, CATPRODUCT), Fusion 360 (F3D) і інших. Програма надає можливість:

- завантажувати і переглядати CAD моделі з вкладень електронної пошти, локального сховища пристрою, Dropbox, Box, Buzzsaw, OneDrive тощо;

- переходити між великомасштабними 2D i 3D-моделями CAD; вимірювати відстань, кут або область між точками на кресленні;

- співпрацювати з клієнтами або колегами над одним проектом одночасно;

- робити коментарі безпосередньо на ваших конструкціях і стежити за змінами;

- запрошувати нових членів приєднатися до вашого проекту в стадії розробки і спільно працювати ним. 
Такий широкий набір інструментарію надає можливість комплексно використовувати в навчальному процесі локальні, мобільні програми та хмарні сервіси 3 автоматизованого проектування та спільної роботи над конструкторськими проектами (рис. 1).

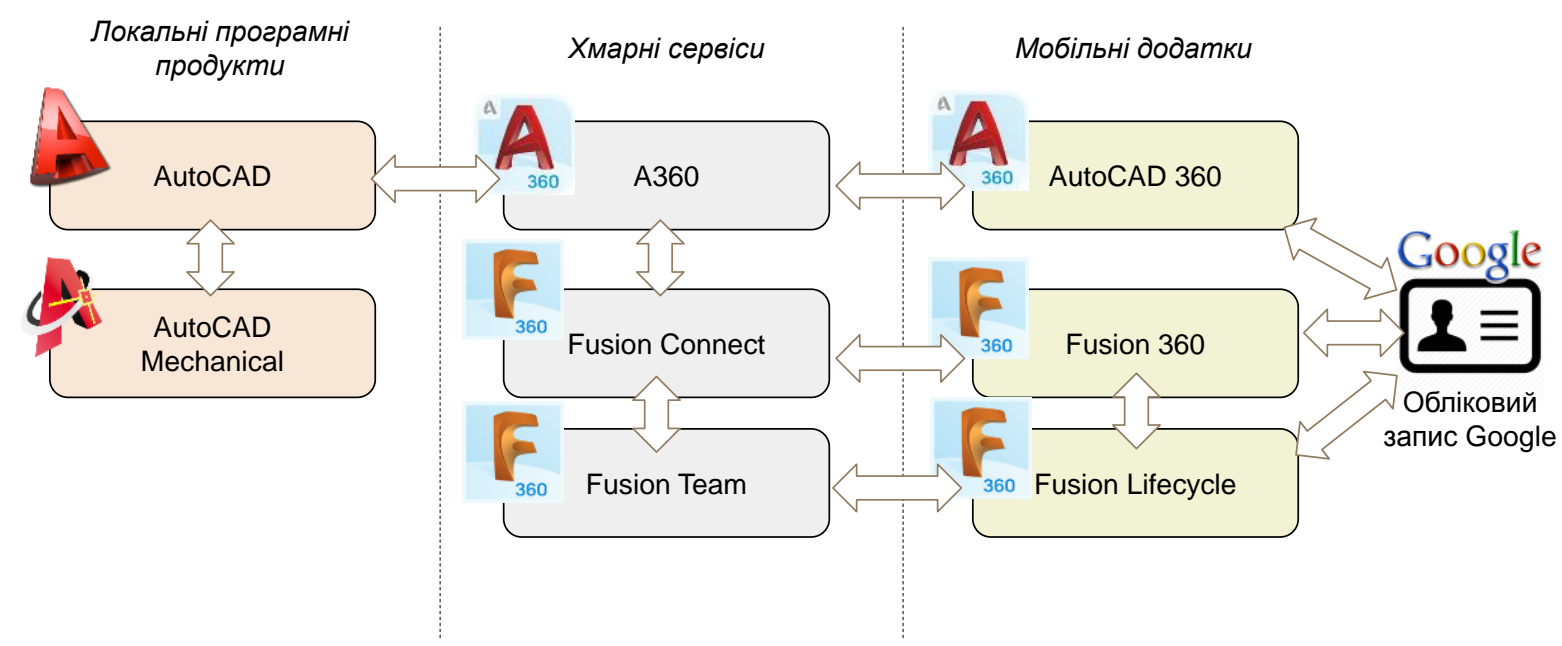

Рис. 1. Комплексне використання продуктів Autodesk у навчанні майбутніх фахівців з прикладної механіки

Серед всіх можливостей даного комплексу програм слід відзначити підтримку авторизації через обліковий запис Google та інтеграцію з хмарними сервісами, що надаються цією компанією. Таким чином студенти отримають можливість актуалізувати знання та навички, отримані під час вивчення фундаментальних дисциплін, а використані засоби навчання утворюватимуть цілісну систему з типовим способом доступу (рис. 2).

Дана модель передбачає використання різного апаратного та програмного забезпечення, що доступне користувачу в певний момент часу. Для доступу до всіх необхідних сервісів в загальному випадку достатньо будь-якого Інтернет браузеру, але можуть використовуватись і локальні та мобільні програми, що працюють під управлінням операційних систем Windows, Chrome, Android тощо. 


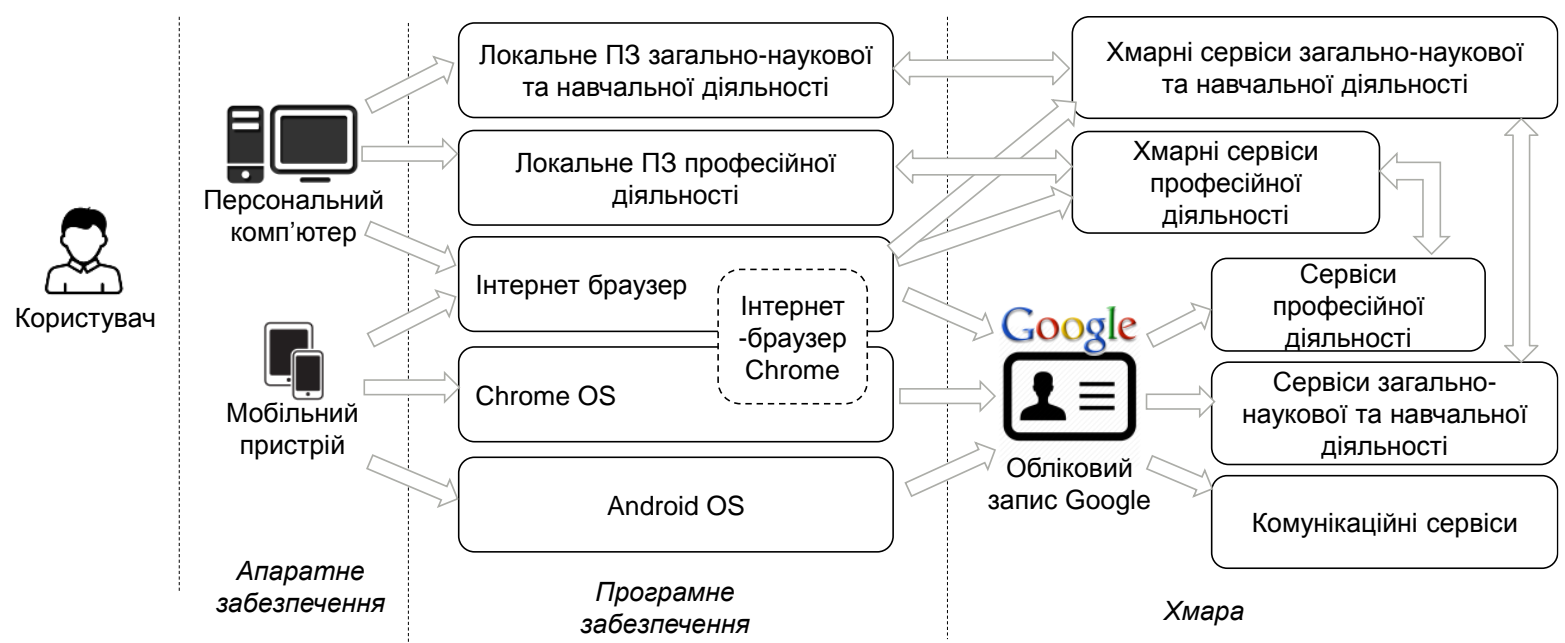

Рис. 2. Модель типового доступу до хмаро орієнтованих засобів загальнонаукової, навчальної та професійної діяльності

Хмарні сервіси загально-наукової та професійної діяльності можуть використовуватись як самостійно, так і в інтеграції з хмарними сервісами Google. В останньому випадку обліковий запис Google стає єдиною точкою доступу до різних сервісів, мобільних додатків, хмарних сховищ та комунікаційних засобів, що забезпечить як ефективну організацію навчального процесу, так і професійної діяльності. Враховуючи, що сервіси Google активно використовуються у навчанні майбутніх фахівців з прикладної механіки під час викладанні загально-наукових дисциплін [8], застосування програм компанії Autodesk буде природнім 3 точки зору розвинення IКТ-компетентностей майбутніх інженерів-механіків.

Таким чином, нами визначено потребу у розвитку ІКТ-компетентності бакалаврів 3 прикладної механіки, зокрема умінь і здатності добирати i використовувати мобільні та хмаро орієнтовані засоби професійної діяльності. На основі визначених критеріїв добору хмаро орієнтованих інструментів професійної діяльності, було проаналізовано близько 30 сучасних хмарних сервісів та мобільних програм, що можуть бути використані в професійній діяльності інженерів-механіків. Детально розглянуто деякі 3 них. Аналіз показав, що використання хмарних сервісів Autodesk та їх інтеграція 3 хмарними сервісами Google $\epsilon$ доцільним для професійно-практичної підготовки 
майбутніх фахівців з прикладної механіки, сприяє ефективному розвитку професійної та ІКТ-компетентності майбутніх інженерів-механіків. Запропонована система засобів та модель єдиного доступу до хмарних сервісів загально-наукової, навчальної та професійної діяльності можуть бути природньо інтегровані у хмаро-орієнтоване освітньо-наукове середовище ВНЗ [10] та застосовані до професійно-практичної підготовки студентів інших інженерних спеціальностей.

\section{Література}

1. AutoCAD 360 App [Electronic resource]. - Mode of access: http://www.autodesk.com/products/autocad-360/overview

2. Autodesk | 3D Design, Engineering \& Entertainment Software [Electronic resource]. - Mode of access: http://www.autodesk.com/

3. Fusion $360 \mid$ Free Software for Students, Educators | Autodesk [Electronic resource]. - Mode of access: http://www.autodesk.com/products/fusion-360/studentsteachers-educators

4. Mechanical Engineering Design Software | AutoCAD Mechanical [Electronic resource]. $\quad-\quad$ Mode of access

http://www.autodesk.com/products/autocad-mechanical/overview

5. Project Collaboration In The Cloud | A360 | Autodesk [Electronic resource]. - Mode of access : http://www.autodesk.com/products/a360/overview

6. Рассовицька М. В. Аналіз структури ІКТ-компетентностей бакалаврів 3 прикладної механіки [Електронний ресурс] / Рассовицька Марина Віталіївна // III Всеукраїнська науково-практична конференція молодих учених «Наукова молодь-2015». - - $10.12 .2015 \quad$ - $\quad$ Режим доступу https://docviewer.yandex.ua/?url=http\%3A\%2F\%2Fconf.iitlt.gov.ua\%2FImages\%2F Files\%2Frassovitskaya_195_1448966395_file.doc\&name=rassovitskaya_195_14489 66395_file.doc\&lang=uk\&c=56b1e140a2eb

7. Рассовицька М. В. Використання хмарних технологій у навчанні інформатики студентів інженерних спеціальностей [Електронний ресурс] / 
М. В. Рассовицька // Звітна наукова конференція Інституту інформаційних технологій і засобів навчання НАПН України : Матеріали наукової конференції. - Київ : ІІТЗН НАПН України, 2014. - С. 198-200. - Режим доступу : http://lib.iitta.gov.ua/4534/1/\%D0\%A2\%D0\%B5\%D0\%B7\%D0\%B8\%D0\%BA\%D0\%BE\%D0\%BD\%D1\%84-IITZN-2014.pdf

8. Рассовицька М. В. Модель використання Google Apps у комбінованому навчанні інформатики студентів інженерних спеціальностей / Рассовицька М. В., Стрюк А. М. // Тези доповідей науково-практичного семінару «Хмарні технології в сучасному університеті» (ХТСУ-2015) : Черкаси, 24 березня 2015 р. Семінар присвячений 55-річчю від дня заснування ЧДТУ / Міністерство освіти і науки України, Черкаський державний технологічний університет, Інститут інформаційних технологій і засобів навчання НАПН України, Криворізький національний університет, Національний педагогічний університет імені М. П. Драгоманова, Черкаський національний університет імені Богдана Хмельницького. - Черкаси : ЧДТУ, 2015. - С. 42-44.

9. Стрюк А. М. Використання хмарних технологій у комбінованому навчанні інформатики студентів інженерних спеціальностей / А. М. Стрюк, М. В. Рассовицька // Вісник Дніпропетровського університету імені Альфреда Нобеля. Серія: Педагогіка і психологія. - 2015. - № 1 (9). - С. 221-226.

10. Стрюк А. М. Система хмаро орієнтованих засобів навчання як елемент інформаційного освітньо-наукового середовища ВНЗ [Електронний ресурс] / Стрюк Андрій Миколайович, Рассовицька Марина Віталіївна // Інформаційні технології і засоби навчання. - 2014. - Том 42. - №4. - С. 150158. - - Режим доступу

http://journal.iitta.gov.ua/index.php/itlt/article/download/1087/829 